\title{
Right atrial tuberculoma: Computed tomography and magnetic resonance imaging
}

Abdul M. Alkhulaifi, MB, BCh, LRCP, MS, FRCS(CTh), and Cornelia S. Carr, BSc, MB, BS, MS, FRCS(CTh), Doha, Oatar

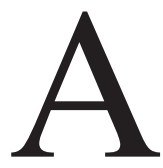

31-year-old Eritrean man presented with a 10-day history of fever, cough, and dyspnea. He was pyrexial and tachypneic with right lung crepitations and a discharging scrotal sinus. Chest radiography showed patchy consolidation of the right lower zone. Pneumonia was diagnosed, and antimicrobial therapy was started. Sputum was negative for acid-fast bacilli (AFB), and blood cultures grew Gram-positive cocci.

Computed tomography (Figure 1) showed massive alveolar opacities; pleural, pericardial, and peritoneal thickening; ascites; and a right atrial mass. A transesophageal echocardiogram confirmed a $3 \times 4$-cm mass encroaching into the right atrium related to the superior vena cava. The patient's condition deteriorated, and he required intubation. He was human immunodeficiency virus negative, and pleural and ascitic fluids were AFB negative, but antituberculosis treatment was started for presumed miliary tuberculosis and right atrial mass. Peritoneal biopsy (via laparoscopy) showed epithelioid granulomas.

He was extubated after 7 days, and in view of the atrial mass, warfarin was started. Endocardial biopsy (under transesophageal echocardiogram) showed myocardial fibers, necrotic foci, and inflammatory cells, but no myxoma or malignancy. The scrotal wound was AFB negative, and there was azoospermia. Because there was no hemodynamic compromise, we decided to assess the patient with serial imaging. Magnetic resonance imaging performed 4 months later (Figure 2) showed a marked reduction in size $(3 \times 2 \times 2.5 \mathrm{~cm})$ with peripheral gadolinium enhancement and inflammation/obliteration of the seminal vesicle lumens.

This patient presented with overwhelming sepsis, and initially it was thought that the atrial mass may be incidental, but he remains well with warfarin and antituberculous treatment. The combination of the patient's ethnic origin, pneumonic process, sepsis, and discharging scrotal wound led to the diagnosis of tuberculosis, although no AFBs have ever been isolated. Previous myocardial tuberculomas have regressed with antituberculosis treatment, ${ }^{1}$ adding support to our diagnosis of right atrial tubercu-

\footnotetext{
From the Cardiac Surgery Department, Hamad General Hospital, Doha, Qatar.

Received for publication Sept 24, 2006; accepted for publication Oct 24, 2006.

Address for reprints: Cornelia S. Carr, BSc, MB, BS, MS, FRCS(CTh), CCS Department, Hamad General Hospital, PO Box 3050, Doha, Qatar (E-mail: noahalkh@talk21.com).

J Thorac Cardiovasc Surg 2007;133:808

$0022-5223 / \$ 32.00$

Copyright $\odot 2007$ by The American Association for Thoracic Surgery doi:10.1016/j.jtcvs.2006.10.047
}

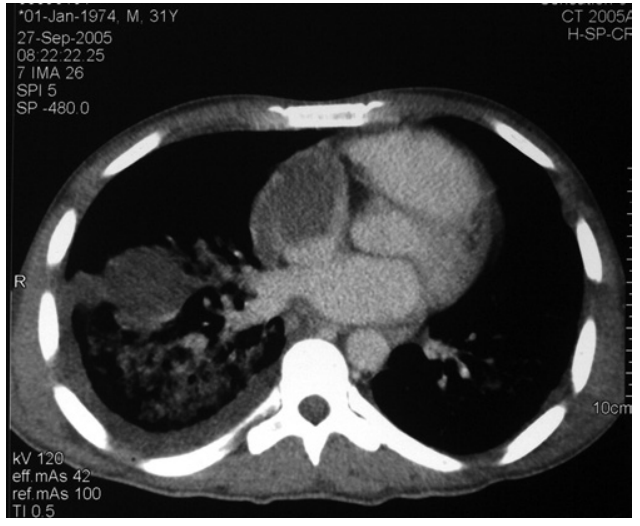

Figure 1. Computed tomography showing mass encroaching into the right atrial lumen.

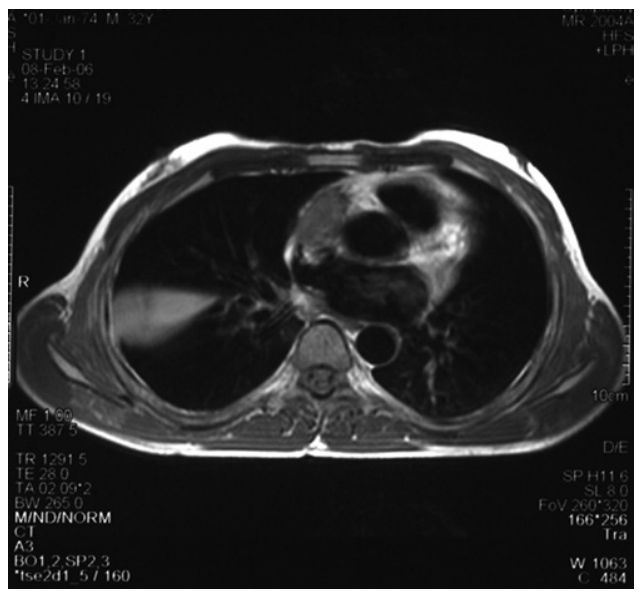

Figure 2. Magnetic resonance image showing reduction in size of the right atrial mass.

loma, which also exhibits the magnetic resonance imaging characteristics of tuberculoma. ${ }^{2}$

\section{References}

1. O'Neill PG, Rokey R, Greenberg S, Pacifico A. Resolution of ventricular tachycardia and endocardial tuberculoma following antituberculosis therapy. Chest. 1991;100:1467-9.

2. Jagia P, Gulati GS, Sharma S, Goyal NK, Gaikwad S, Saxena A. MRI features of tuberculoma of the right atrial myocardium. Pediatr Radiol. 2004;34:904-7. 